\title{
Efeito de Herbicidas Aplicados em Pré-Emergência e Momentos de Início da IrRigação no Crescimento de Plantas de ArRoz ${ }^{1}$
}

\author{
Effect of Herbicides Applied in Pre-Emergence and Water Management on Rice Growth \\ CONCENÇO, G. ${ }^{2}$, ANDRES, A. ${ }^{3}$, LOPES, N.F. ${ }^{4}$, MORAES, D.M. ${ }^{4}$, RESENDE, R.G. ${ }^{5}$ e \\ FONTOURA, T.P. ${ }^{5}$
}

\begin{abstract}
RESUMO - O objetivo deste trabalho foi avaliar os herbicidas penoxsulam, inibidor da ALS, e clomazone, inibidor da síntese de carotenóides, aplicados em pré-emergência em doses crescentes, submetidos a diferentes entradas de água (19, 24 e 29 dias após emergência DAE), sobre o estabelecimento inicial da cultura e crescimento das plantas de arroz BRS Pelota. O penoxsulam apresentou baixa intoxicação tanto na parte aérea quanto nas raízes das plantas de arroz, com efeitos mais acentuados sobre as raízes. O início da irrigação até os $24 \mathrm{DAE}$ associado a doses de até $54 \mathrm{~g} \mathrm{ha}^{-1}$ de penoxsulam e de até $300 \mathrm{~g} \mathrm{ha}^{-1}$ de clomazone ocasionaram danos mínimos à parte aérea e às raízes do arroz BRS Pelota. No entanto, doses de clomazone acima das indicadas, associadas à irrigação da lavoura aos 19 DAE, causaram forte intoxicação às plantas de arroz.
\end{abstract}

Palavras-chave: clomazone, penoxsulam, Oryza sativa, crescimento.

\begin{abstract}
The objective of this work was to evaluate the effect of the herbicides penoxsulam (ALS-inhibiting herbicide) and clomazone (carotene biosynthesis-inhibiting herbicide) applied in pre-emergence at increasing rates, submitted to water management (19, 24 and 29 days after emergence -DAE) on the initial establishment and growth of rice BRS Pelota. Penoxsulam showed low phytotocixity both in shoots and roots of rice plants, with greater effects on the roots. Water availability until 24 DAE associated with penoxsulam rates up to $54 \mathrm{~g} \mathrm{ha}^{-1}$ and clomazone rates up to $300 \mathrm{~g} \mathrm{ha}^{-1}$ resulted in minimal damages to rice shoots and roots. However, clomazone rates above the recommended, associated with water availability 19 DAE caused high phytotoxicity to rice plants.
\end{abstract}

Keywords: clomazone, penoxsulam, Oryza sativa, growth.

\section{INTRODUÇÃO}

O arroz é considerado planta semi-aquática, podendo ser cultivado tanto em solo submerso como em solos bem drenados (Gomes \& Azambuja, 2003). Em razão de sua versatilidade, é um dos cereais mais cultivados no mundo, especialmente na Ásia. No Brasil, cerca de 1,3 milhão de hectares são cultivados com arroz irrigado, sendo 77\% no Rio Grande do Sul (Gomes et al., 1999, 2002).

As plantas daninhas concorrem com as de arroz por luz, água e nutrientes, constituindose em um dos principais fatores limitantes da produtividade nas lavouras de arroz irrigado do Rio Grande do Sul e de Santa Catarina (Andres \& Machado, 2004; SOSBAI, 2003).

Recebido para publicação em 4.8.2005 e na forma revisada em 5.5.2006.

2 Mestrando em Fisiologia Vegetal, PPGFV, Universidade Federal de Pelotas - UFPel, bolsista CNPq; estagiário da Embrapa Clima Temperado, 96010-900 Capão do Leão-RS, <gconcenco@ yahoo.com.br>; ${ }^{3}$ Pesquisador de Herbologia, Embrapa Clima Temperado, Capão do Leão-RS; ${ }^{4}$ Prof. Dr., UFPel/IB, Campus Universitário, Caixa Postal 354, 96010-900 Capão do Leão-RS. ${ }^{5}$ Estudante de graduação da UFPel; estagiários da Embrapa Clima Temperado, Capão do Leão-RS. 
Independentemente do sistema de cultivo, o controle químico é a principal alternativa de controle de plantas daninhas, pela eficiência e praticidade (Andres \& Machado, 2004).

Quanto aos herbicidas recomendados para a cultura do arroz, os inibidores da enzima ALS podem reduzir o crescimento das plantas de arroz, principalmente do sistema radical, quando em doses inadequadas (Leite et al., 1998). O alongamento das raízes é prejudicado em altas doses, principalmente pelas reduções do conteúdo de água das raízes, causador da pressão de turgescência, que é responsável pelo alongamento celular (Leite et al., 1998; Concenço et al., 2004).

O início da irrigação está associado ao controle de plantas daninhas, pela eliminação do oxigênio disponível e inibição do processo de germinação. Atualmente, o uso de herbicidas com atividade residual prolongada no solo possibilita retardar o início da irrigação, pois a inibição que seria exercida pela água é substituída pela ação do herbicida pré-emergente. No entanto, a extensão desse período depende do produto e dose empregada, das espécies e níveis de infestação de plantas daninhas e das condições ambientais, podendo variar de 15 a 30 DAE, dependendo do manejo de plantas daninhas adotado (Andres \& Machado, 2004).

A presença da lâmina de água pode reduzir o perfilhamento, incrementar o alongamento do colmo, a síntese e a resposta ao etileno e estimular o surgimento de aerênquima (Bressan et al., 2004). Nessas condições, o coleóptilo do arroz emerge e se torna a rota de difusão de $\mathrm{O}_{2}$ para o resto da planta. Por isso, ele não deve sofrer nenhum tipo de dano, tampouco injúrias causadas pela utilização de herbicidas préemergentes, sob risco de comprometer a rápida adaptação da cultura ao ambiente hipóxico.

A controvérsia sobre o momento ideal de início de irrigação ocorre quando os aspectos ligados a otimização do uso da água, impacto ambiental, custo da energia, infestação de Oryzophagus oryzae, controle de plantas daninhas e ecofisiologia da cultura conflitam entre si (Freitas, 2004).

O objetivo deste estudo foi avaliar, em campo, a influência do período de irrigação associado a doses crescentes dos herbicidas penoxsulam e clomazone sobre o estabelecimento inicial e o crescimento da parte aérea e das raízes das plantas de arroz.

\section{MATERIAL E MÉTODOS}

O experimento foi instalado em Capão do Leão/RS, no ano agrícola 2004/05, em Planossolo Hidromórfico Eutrófico típico (Pinto et al., 1999). O delineamento experimental foi o de blocos ao acaso com tratamentos dispostos em esquema de parcelas subsubdivididas com quatro repetições. As parcelas mediam $10 \mathrm{~m}^{2}$, com área útil de $6,4 \mathrm{~m}^{2}$, sendo constituídas por três épocas de entrada da água $(19,24$ e 29 dias após a emergência das plantas de arroz - DAE); as subparcelas, pelos herbicidas penoxsulam e clomazone; e as subsubparcelas, formadas pelas doses, classificadas, respectivamente, em testemunha livre de competição ( $0 \mathrm{~g} \mathrm{ha}^{-1}$ ), baixa (18 e $300 \mathrm{~g} \mathrm{ha}^{-1}$ ), intermediária (36 e $400 \mathrm{~g} \mathrm{ha}^{-1}$ ), média (54 e $500 \mathrm{~g} \mathrm{ha}^{-1}$ ) e alta (72 e $600 \mathrm{~g} \mathrm{ha}^{-1}$ ).

O solo foi preparado no dia 19.10.2004 com uma aração, duas gradagens e duas passadas de rolo. A semeadura foi realizada com cultivar BRS Pelota no sistema convencional de cultivo do arroz, no dia 26.10.2004, na densidade de $150 \mathrm{~kg} \mathrm{ha}^{-1}$, utilizando-se de semeadora-adubadora SHM-1113 de 11 linhas espaçadas entre si de $0,175 \mathrm{~m}$, em solo corrigido. A adubação foi realizada na linha de semeadura, conforme análise de solo e recomendações da Rolas (1995). A emergência de $50 \%$ das plântulas ocorreu nove dias após a semeadura.

Os herbicidas foram pulverizados um dia após a semeadura, nas primeiras horas da manhã, utilizando-se pulverizador de pressão constante propelido por $\mathrm{CO}_{2}$ e barra com quatro bicos Teejet 110.015 tipo leque, espaçados de $0,5 \mathrm{~m}$, com vazão de $150 \mathrm{~L} \mathrm{ha}^{-1}$. Não havia plantas daninhas ou plantas da cultura emergidas no momento da aplicação.

A densidade média de plantas de arroz foi avaliada por meio de duas subamostragens de $0,25 \mathrm{~m}^{2}$ por unidade experimental imediatamente antes da irrigação da parcela, portanto, aos 19, 24 e 29 DAE. A densidade do arroz foi expressa em plantas por metro quadrado, no momento do início da irrigação. As demais variáveis, descritas a seguir, foram avaliadas aos 38 DAE. A altura das plantas foi medida 
da superfície do solo até a extremidade da folha mais alta, em cinco plantas.

As fitomassas fresca (MF) e seca (MS) da parte aérea foram determinadas em uma planta por unidade experimental. Após corte rente ao solo, a MF foi imediatamente aferida. Em seguida, a parte aérea foi acondicionada em saco de papel e colocada na estufa de circulação forçada de ar a $60{ }^{\circ} \mathrm{C}$ até massa constante, determinando-se a MS. O conteúdo de água (CA\%) na parte aérea foi estimado pela fórmula: $\mathrm{CA} \%=100(\mathrm{MF}-\mathrm{MS}) / \mathrm{MF}$.

Para obtenção do sistema radicular, amostras de solo de $0,001 \mathrm{~m}^{3}$ foram coletadas com o auxílio de cano de PVC de $100 \mathrm{~mm}$. O cano foi inserido no solo sobre a linha de plantio até a profundidade de $0,125 \mathrm{~m}$, sendo flexionado e puxado para cima. O sistema radicular presente no volume de solo coletado foi lavado individualmente sobre peneira e seco em papeltoalha, para eliminar o excesso de água, sendo pesado para obter a MF. Em seguida, teve seu volume aferido em proveta graduada, utilizando-se o método de volume de líquido deslocado. A amostra foi acondicionada em sacos de papel e colocada para secar em estufa de circulação forçada de ar a $60{ }^{\circ} \mathrm{C}$ por três dias, para determinar a MS. O conteúdo de água (CA\%) nas raízes foi calculado semelhantemente ao da parte aérea.

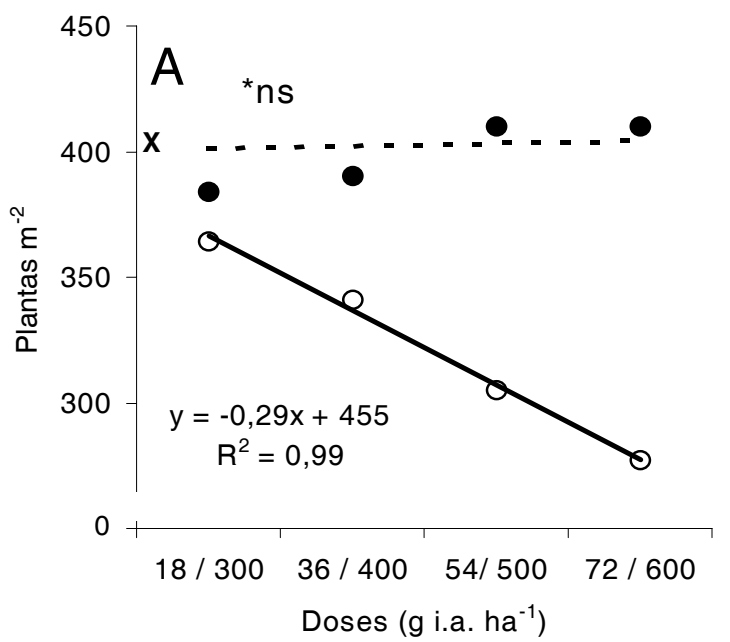

Os dados foram submetidos à análise de variância pelo teste $\mathrm{F}$ a $5 \%$, sendo avaliados entrada de água (E), herbicida (H), dose (D), (E) $x(H),(E) \times(D),(H) \times(D)$ e $(E) \times(H) \times(D)$. Foram traçadas regressões em nível de 5\% de probabilidade, de acordo com as interações significativas da análise de variância.

\section{RESULTADOS E DISCUSSÃO}

A densidade de plantas de arroz não foi afetada pelo herbicida penoxsulam, mas foi significativamente $(\mathrm{P} d " 0,05)$ reduzida pelo incremento nas doses de clomazone (Figura 1A). O atraso no início da irrigação não afetou a densidade de plantas quando tratadas com penoxsulam, porém a irrigação imediata aumentou o nível de intoxicação pelo clomazone, reduzindo a densidade de plantas de arroz (Figura 1B), ressaltando-se que as duas maiores doses de clomazone não são indicadas pela pesquisa para o planossolo onde foi instalado o experimento.

A altura de plantas aos $38 \mathrm{DAE}$ foi reduzida por ambos os herbicidas com o início da irrigação no fim do período recomendado (Figura 2A, B). A MS da parte aérea não foi alterada nas parcelas tratadas com penoxsulam, independentemente de dose ou início da irrigação. Por sua vez, o clomazone causou maior intoxicação às plantas de arroz quando submetido

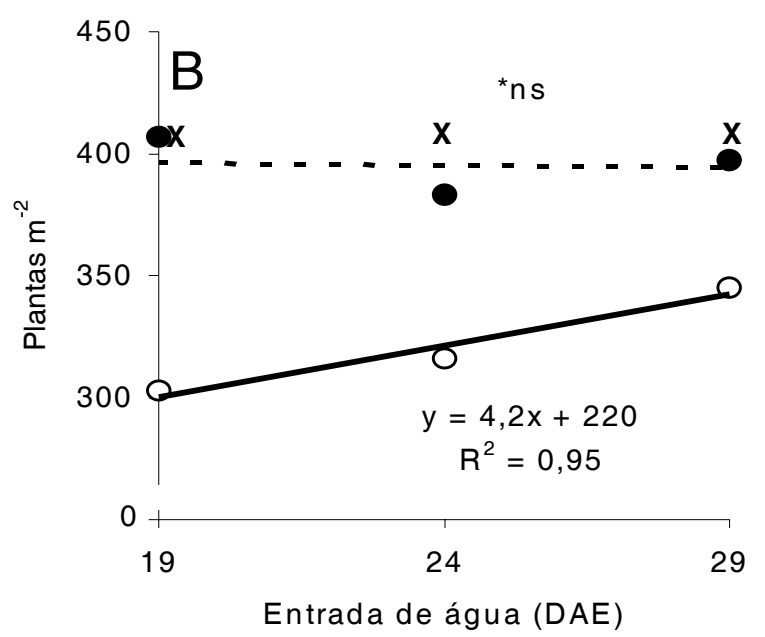

Figura 1 - Densidade de plantas de arroz BRS Pelota no início da irrigação em função de doses dos herbicidas (A) penoxsulam (•), clomazone $(\mathrm{O})$, testemunha $(\mathrm{X})$ e épocas de entrada de água $(\mathrm{B})$ após a emergência das plântulas. $(\mathrm{H}) \mathrm{x}(\mathrm{D})=5 \%$; $(\mathrm{H}) \mathrm{x}(\mathrm{E})=5 \%$. 
à entrada de água na lavoura mais cedo, resultando em plantas menores aos $19 \mathrm{DAE}$, mostrando menor intoxicação após a aplicação do herbicida nas parcelas em que o início da irrigação foi mais tarde (Figura 3). No entanto, salienta-se que, a fim de que seja possível a flexibilização da irrigação (início da inundação mais tardio), é essencial a presença de umidade em abundância no solo para o adequado desenvolvimento da planta (Horiguchi, 1995).

A densidade populacional de arroz (Figura 1B) e a MS da parte aérea (Figura 3) aumentaram com o início da irrigação mais tarde,

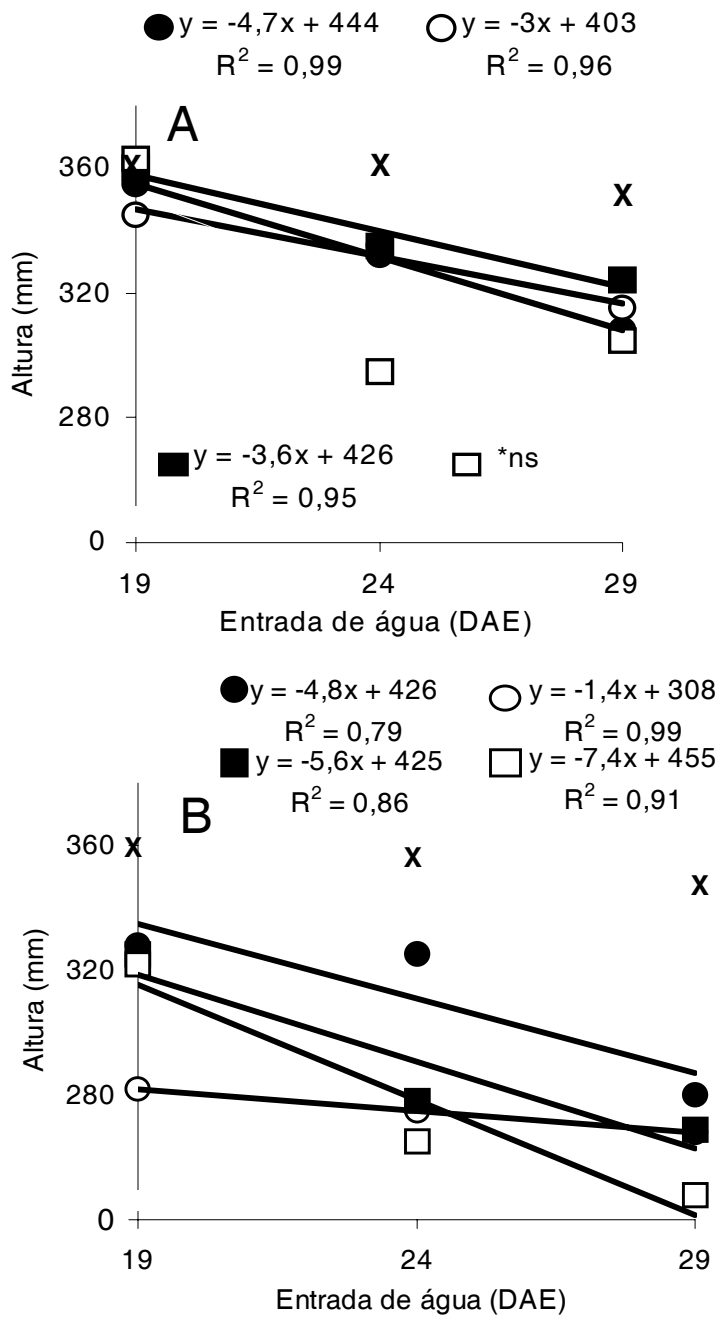

Figura 2 - Altura de plantas de arroz BRS Pelota aos 38 DAE em função de épocas de início de irrigação e de doses de penoxsulam (A) e clomazone (B), em que (x) = testemunha; (O) = baixa; $(\mathrm{O})$ = intermediária; $(\mathbf{\square})$ = média; $(\square)=$ alta. (D) $\mathrm{x}(\mathrm{E})=5 \%$. quando tratadas com clomazone. Este herbicida é altamente solúvel em água (> $1.000 \mathrm{mg} \mathrm{L}^{-1}$ ) e conseqüentemente, a presença de água em abundância no solo facilita a sua absorção pelas plantas (Vencill, 2002). Essa solubilidade o torna eficiente para aplicação em condições de solo inundado (Noldin \& Eberhardt, 2001), com o inconveniente de potencializar seu efeito fitotóxico na presença da água (Vernetti Jr. et al., 2001). A redução na densidade de plantas com incremento na MS individual destas resultou, provavelmente, da morte de plantas causada por doses de clomazone acima das indicadas para o solo em estudo, em associação com o início da irrigação mais adiantado. Com menor número de plantas por metro na linha, em doses mais altas (Figura 1A), as plantas produziram maior fitomassa (Figura 3), devido à menor competição por espaço, nutrientes e luz e mostraram menor altura, em razão do crescimento radial e favorecimento do perfilhamento (Figura 2B).

A MF de raízes não foi alterada quando as plantas foram submetidas aos tratamentos com penoxsulam, porém reduziu com o incremento da dose de clomazone (Figura 4). Por outro lado, como é característico dos inibidores da enzima ALS (Leite et al., 1998), observou-se redução na MS de raízes quando se aumentou a dose de penoxsulam (Figura 5); na maior dose

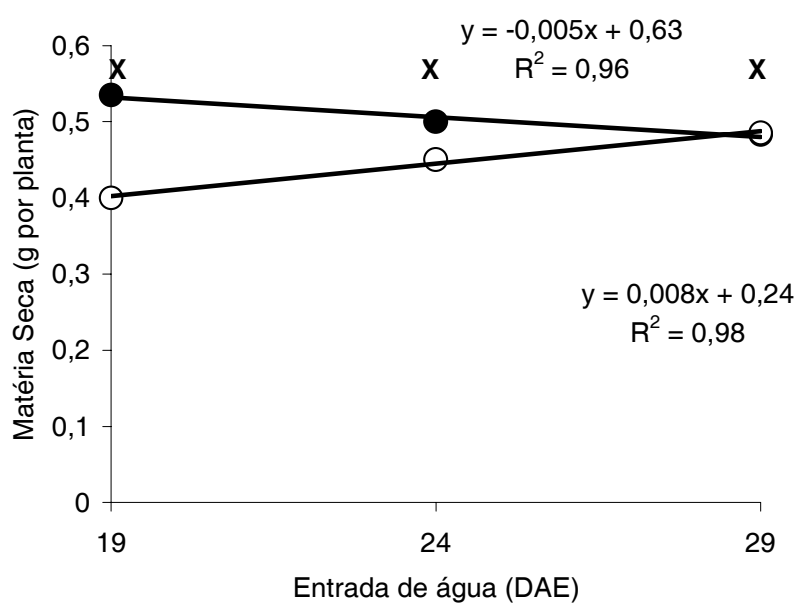

Figura 3 - Matéria seca da parte aérea de plantas de arroz BRS Pelota aos 38 DAE em função de épocas de início de irrigação e dos herbicidas penoxsulam $(\bullet)$, clomazone $(\mathrm{O})$ e testemunha (X). Média das doses dos herbicidas. $(\mathrm{H}) \mathrm{x}$ $(\mathrm{E})=5 \%$. 
(72 g i.a. ha-1), a fitomassa seca de raízes foi menor que aquela quando sob efeito do clomazone. O volume de raízes foi reduzido com o incremento na dose do penoxsulam, mas não foi afetado pelo incremento nas doses de clomazone. Mesmo com redução no volume de raizes, o penoxsulam mostrou resultados superiores aos obtidos com clomazone (Figura 6), pois nas parcelas submetidas ao clomazone houve alto índice de mortalidade de plantas (Figura 1A, B).

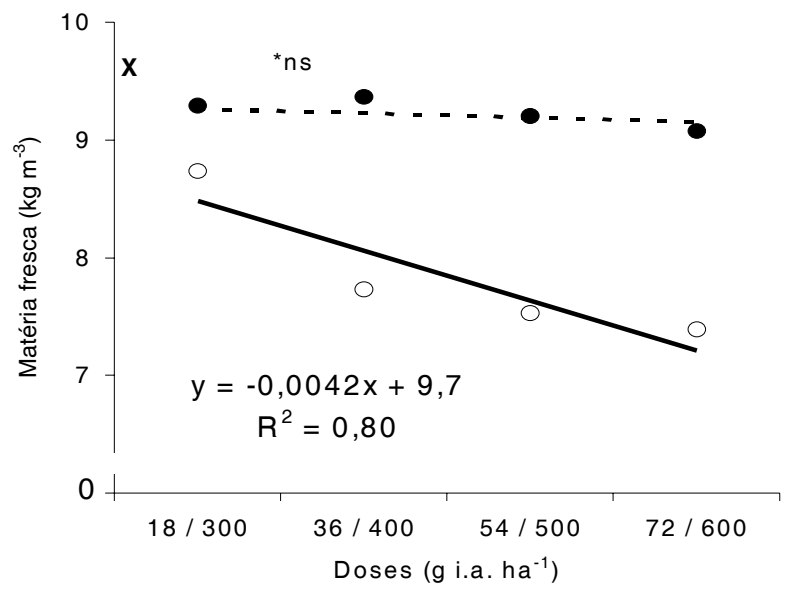

Figura 4 - Matéria fresca de raízes de arroz BRS Pelota por volume de solo em função de doses dos herbicidas penoxsulam $(\bullet)$, clomazone $(\mathrm{O})$ e testemunha $(\mathrm{X})$ aos 38 DAE. Média das entradas de água. $(H) x(D)=5 \%$.

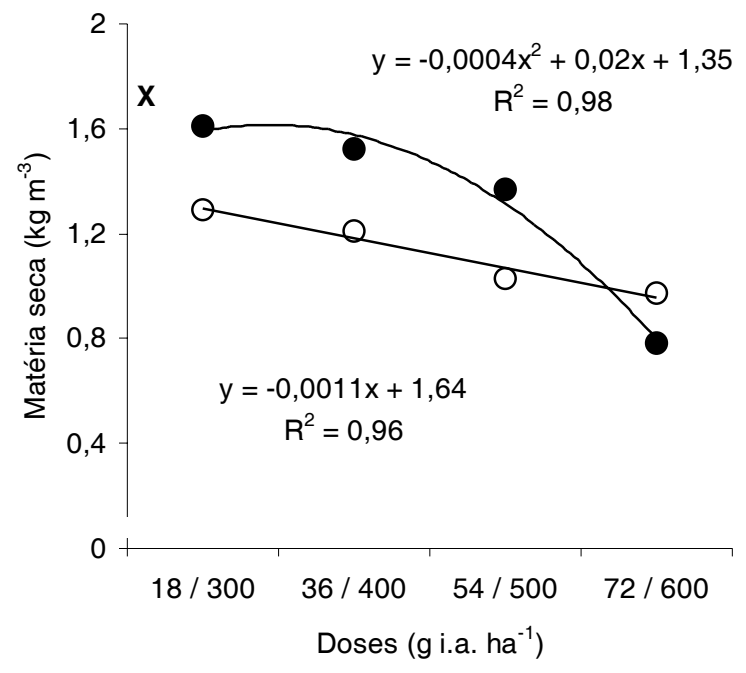

Figura 5 - Matéria seca de raízes de arroz BRS Pelota por volume de solo em função de doses dos herbicidas penoxsulam $(\bullet)$, clomazone $(\mathrm{O})$ e testemunha $(\mathrm{X})$ aos 38 DAE. Média das entradas de água. $(H) x(D)=5 \%$.
O conteúdo de água na parte aérea se manteve com a flexibilização do manejo de água para ambos os herbicidas, corroborando dados anteriores obtidos em laboratório, em que o conteúdo de água das raízes foi severamente reduzido, mas não se alterou na parte aérea (dados não mostrados). Esses resultados podem indicar que a toxicidade do penoxsulam, pulverizado em pré-emergência, é mais intensa no sistema radicular que na parte aérea, concordando com o exposto por Leite et al. (1998) para herbicidas inibidores da ALS e confirmado por Concenço et al. (2004) para este princípio ativo.

O conteúdo de água da planta foi utilizado por muito tempo como um dos primeiros indicadores de intoxicação de herbicidas (Wort, 1964a), sendo pouco empregado nas últimas décadas, devido ao fato de que o comportamento da resposta é particular para princípio ativo e espécie vegetal (Wort, 1964b). No entanto, o conteúdo de água é muito sensivel, podendo ser alterado antes mesmo que outras variáveis o sejam (Wort, 1964a), permanecendo como ferramenta na indicação da presença de intoxicação, porém sem relação direta com o incremento ou a redução do nível de água.

O conteúdo de água nas raízes foi reduzido pelo penoxsulam somente na época mais tardia de início de irrigação (29 DAE), não havendo diferenças para o clomazone (Figura 7). Como

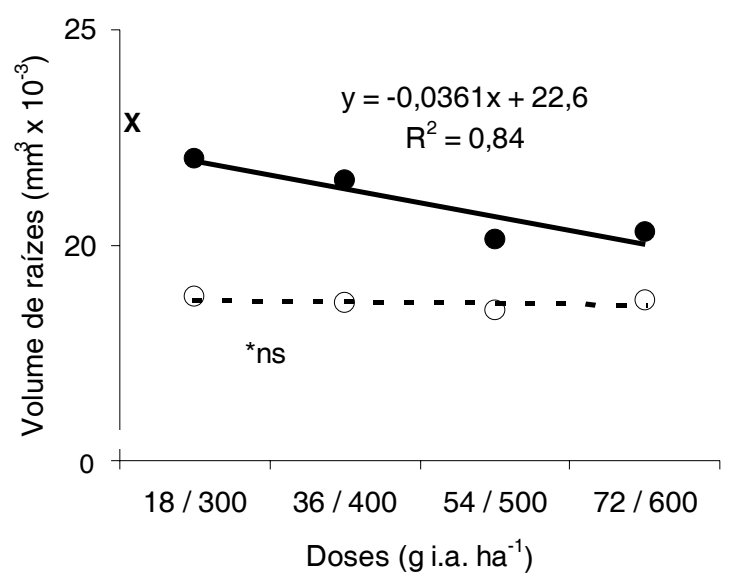

Figura 6 - Volume de raízes de arroz BRS Pelota $\left(\mathrm{mm}^{3}\right.$ por planta) em função de doses dos herbicidas penoxsulam $(\bullet)$, clomazone $(\mathrm{O})$ e testemunha $(\mathrm{X})$ aos 38 DAE. Média das entradas de água. $(\mathrm{H}) \times(\mathrm{D})=5 \%$. 
descrito previamente por Concenço et al. (2004), os sintomas de intoxicação produzidos pelo penoxsulam foram acompanhados por forte redução no conteúdo de água das raízes. Como este sintoma só foi observado na terceira época de irrigação, pode-se afirmar que o início da irrigação da lavoura ocorre até os 24 DAE quando da utilização do herbicida penoxsulam.

O clomazone, ao contrário do penoxsulam, mostrou reduções mais marcantes nas variáveis analisadas na parte aérea (Figuras 1 a 3), de acordo com seu mecanismo de ação, inibidor da biossíntese de carotenóides (Argenta \& Lopes, 1992; Vidal, 2002). Além disso, seu efeito pode estar associado às características do solo em que o experimento foi instalado (Cumming et al., 2002), com baixos teores de argila e de matéria orgânica, portanto com baixa adsorção do herbicida ao solo,
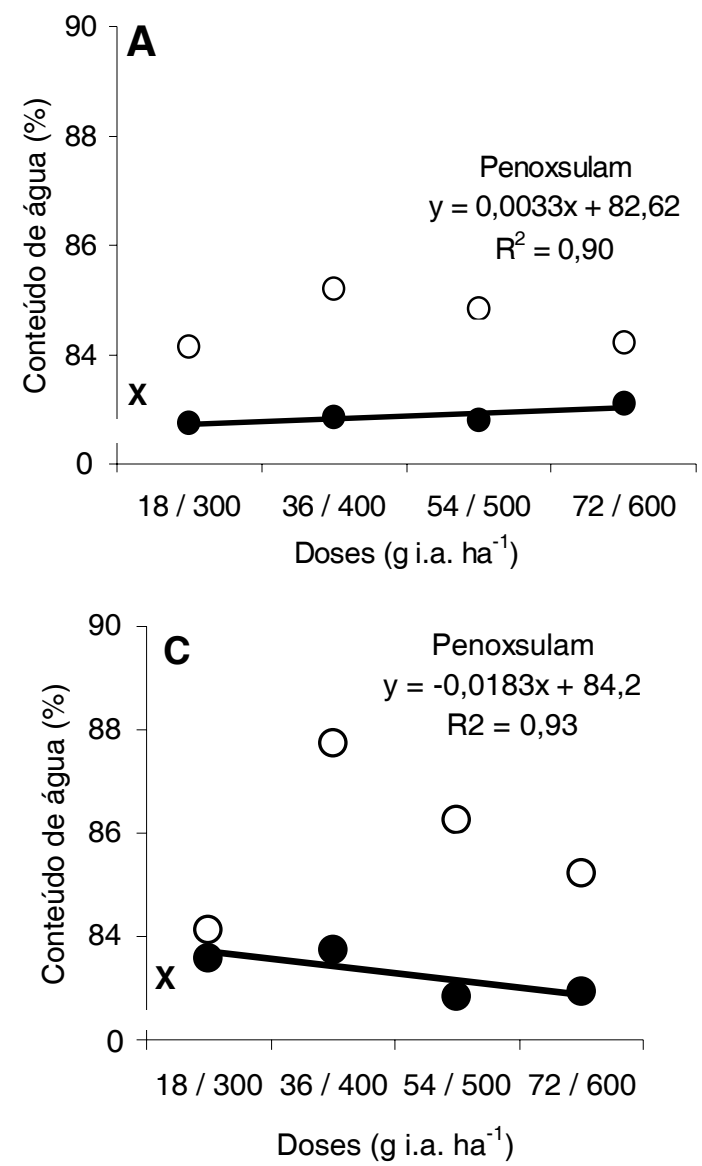

aumentando a disponibilidade. O penoxsulam inibe a biossíntese dos aminoácidos valina, leucina e isoleucina, utilizados em vários processos na planta (Leite et al., 1998). Portanto, ocorre déficit protéico, que interfere fundamentalmente no sistema enzimático e de constituição estrutural (Bressan et al., 2004). No entanto, os sintomas indicaram intoxicação leve sobre as plantas de arroz, mesmo considerando doses acima das indicadas para utilização em condições de lavoura para o penoxsulam.

Este estudo evidenciou que o herbicida penoxsulam, nas doses atualmente testadas pela pesquisa (48 a $54 \mathrm{~g} \mathrm{ha}^{-1}$ ), apresentou baixa intoxicação tanto na parte aérea quanto nas raízes das plantas de arroz, com efeitos mais acentuados sobre as raízes. O atraso da entrada de água até os 24 DAE associado a doses de até 54 g i.a. ha-1 de penoxsulam e de
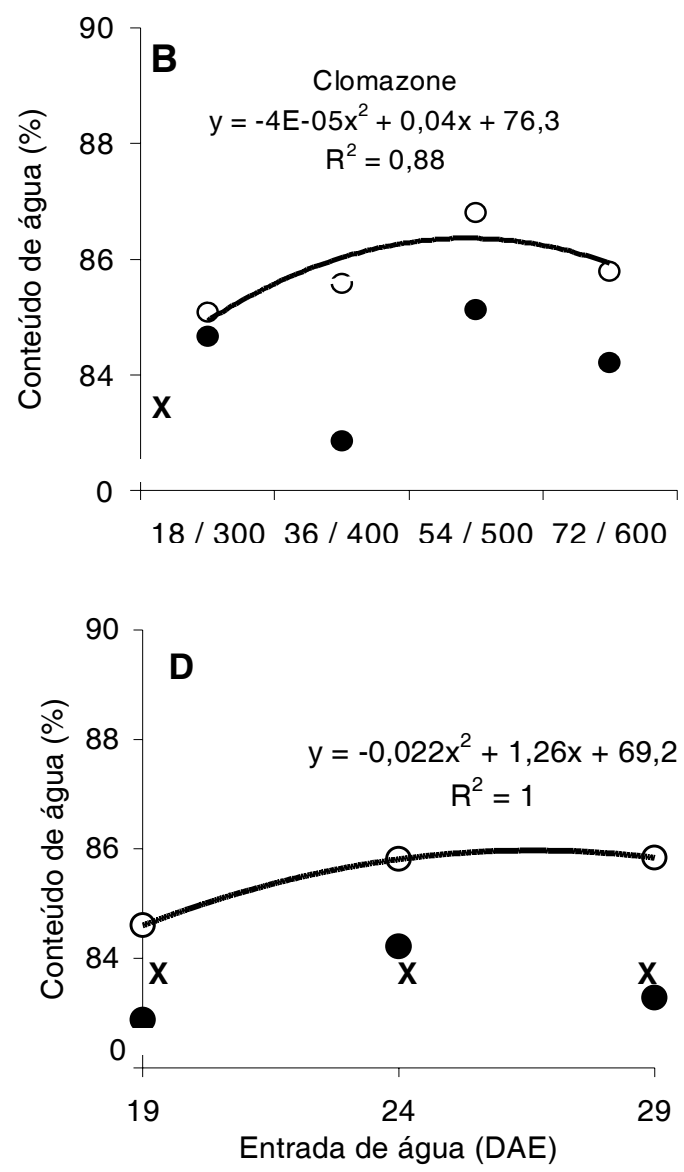

Figura 7 - Conteúdo de água em raízes de arroz BRS Pelota aos 38 DAE em função de doses dos herbicidas penoxsulam (•), clomazone (O) e testemunha (X) e entradas de água aos 19 (A), 24 (B) e 29 (C) DAE e épocas de início da irrigação (D). (E) x $(\mathrm{H}) \mathrm{x}(\mathrm{D})=5 \%$. 
até $300 \mathrm{~g}$ i.a. ha-1 de clomazone ocasionaram danos mínimos à parte aérea e às raízes do arroz BRS Pelota. Entretanto, doses de clomazone acima das indicadas, associadas ao imediato início da irrigação da lavoura, causaram forte intoxicação às plantas de arroz.

\section{LITERATURA CITADA}

ANDRES, A.; MACHADO, S. L. O. Plantas daninhas em arroz irrigado. In: GOMES, A. S.; MAGALHÃES Jr.; A. M. (Eds.). Arroz irrigado no Sul do Brasil. Brasília: Embrapa Informação Tecnológica, 2004. p. 457-546.

ARGENTA, L. C.; LOPES, N. F. Pigment accumulation, photosynthetic, respiratory and growth rates in soybean, rice and watergrass as affected by clomazone doses. R. Bras. Fisiol. Veg., v. 4, n. 2, p. 81-86, 1992.

BRESSAN, R. A.; HASEWAGA, P. M.; LOCY, R. D. Fisiologia do estresse. In: TAIZ, L.; ZEIGER, E. (Eds.). Fisiologia vegetal. 3.ed. Porto Alegre: Artmed, 2004. p. 613-643.

CONCENÇO, G. et al. Efeito do herbicida penoxsulam sobre o desenvolvimento inicial da cultivar de arroz BRSPelota. In: CONGRESSO DE INICIAÇÃO CIENTÍFICA, 13., 2004, Pelotas. Anais... Pelotas: Universidade Federal de Pelotas, 2004. CD-ROM.

CUMMING, J. P. et al. Clomazone dissipation in four Tasmanian topsoils. Weed Sci., v. 50, n. 3, p. 405-409, 2002.

FREITAS, G. D. Desempenho do arroz (Oryza sativa L.) cultivar BRS Pelota e controle de capim-arroz (Echinochloa sp.) submetidos a quatro épocas de entrada de água após aplicação de doses reduzidas de herbicidas. 2004. 54 f. Dissertação (Mestrado em Fitotecnia) Universidade Federal de Pelotas, Pelotas, 2004.

GOMES, A. S. et al. Manejo da água em arroz irrigado: implicações e recomendações técnicas. In: GOMES, A. S.; PAULETTO, E. A. (Eds.) Manejo do solo e da água em áreas de várzea. Pelotas: Embrapa Clima Temperado, 1999. p. 103-200.

GOMES, A. S.; TERRES, A. L.; AZAMBUJA, I. H. V. O arroz irrigado no Rio Grande do Sul: produtividade e perfil do produtor. In: AZAMBUJA, I. H. V. et al. (Eds.). Culturas - Arroz. Porto Alegre: Comissão de Agricultura, Pecuária e Cooperativismo da Assembléia Legislativa do Estado do Rio Grande do Sul, 2002. p. 23-34.

GOMES, A. S.; AZAMBUJA, I. H. V. Uso e manejo de água nas lavouras de arroz do Rio Grande do Sul. In: SIMPÓSIO SUL-BRASILEIRO DE QUALIDADE DE ARROZ, 1., 2003, Pelotas. Anais... Passo Fundo: ABRAPÓS, 2003. p. 57-81.
HORIGUCHI, T. Rhizosphere and root functions. In: MATSUO, T. et al. (Eds.) Science of the rice plant physiology. Tokyo: Food and Agriculture Research Center, 1995. v. 2. p. 221-248.

LEITE, C. R. F.; ALMEIDA, J. C. V.; PRETE, C. E. C. Aspectos fisiológicos, bioquímicos e agronômicos dos herbicidas inibidores da enzima ALS (AHAS). Londrina: Célio Roberto Ferreira Leite, 1998. 68 p.

NOLDIN, J. A.; EBERHARDT, D. S. Alternativas de controle químico de sagitária resistente aos herbicidas inibidores da ALS. In: CONGRESSO BRASILEIRO DE ARROZ IRRIGADO, 2.; REUNIÃO TÉCNICA DA CULTURA DO ARROZ IRRIGADO, 24., 2004, Porto Alegre. Anais... Porto Alegre: IRGA, 2001. p. 574-578.

PINTO, L. F. S. et al. Caracterização de solos de várzea. In: GOMES, A. S.; PAULETTO, E. A. (Eds.). Manejo do solo e da água em áreas de várzea. Pelotas: Embrapa Clima Temperado, 1999. p. 11-36.

REDE OFICIAL DE LABORATÓRIOS DE ANÁLISE DE SOLO - ROLAS. Recomendações de adubação e de calagem para os estados do Rio Grande do Sul e de Santa Catarina. 3.ed. Passo Fundo: SBCS-Núcleo Regional Sul, 1995. 223 p.

SOSBAI. Recomendações técnicas para a cultura do arroz irrigado nos estados do Rio Grande do Sul e de Santa Catarina. Itajaí: EPAGRI, 2003. 121 p.

VENCILL, W. K. Herbicide handbook. 8.ed. Lawrence: WSSA, 2002. 493 p.

VERNETTI Jr., F. J. et al. Efeito de herbicidas no estabelecimento inicial da cultura do arroz irrigado, em sistema pré-germinado: clomazone. In: CONGRESSO BRASILEIRO DE ARROZ IRRIGADO, 2.; REUNIÃO DA CULTURA DO ARROZ IRRIGADO, 24., 2001, Porto Alegre. Anais... Porto Alegre: IRGA, 2001. p. 490-493.

VIDAL, R. A. Ação dos herbicidas. Porto Alegre: R. A. VIDAL, 2002. 89 p.

WORT, D. J. Effects of herbicides on plant composition and metabolism. In: AUDUS, L. J. (Ed.). The physiology and biochemistry of herbicides. New York: Academic Press, 1964a. p. 291-334.

WORT, D. J. Responses of plants to sublethal concentrations of 2,4-D, without and with added minerals. In: AUDUS, L. J. (Ed.). The physiology and biochemistry of herbicides. New York: Academic Press, 1964b. p. 335-342. 